\title{
Надежный тыл для борцов с COVID-19
}

\section{Рассказывает Арина Алексеевна Хартукова, специалист ООО «Сарториус Рус»}

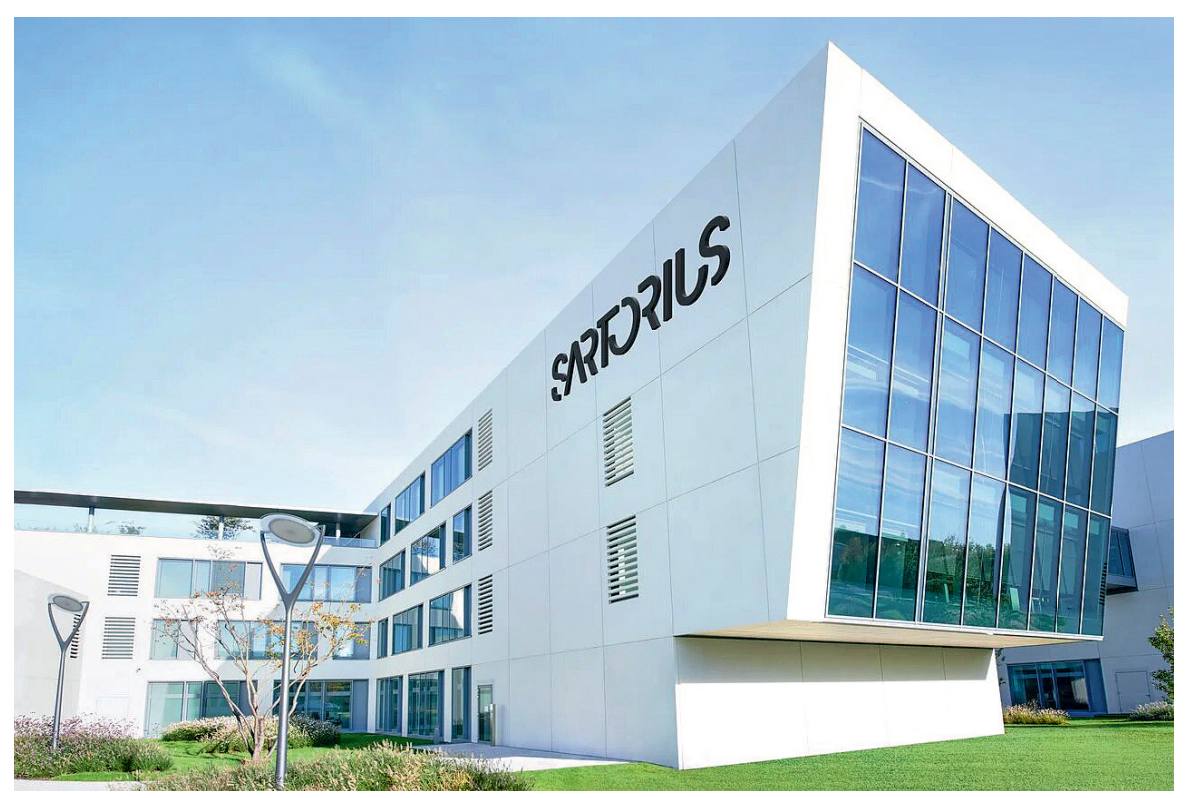

Компания Sartorius, отмечающая в этом году 150-летие, успешно завершила объявленные ранее приобретения, расширив свое портфолио продуктов для лабораторий и фармкомпаний. В самые непростые с точки зрения эпидемической ситуации месяцы в марте и в апреле - она продолжала неукоснительно выполнять свои обязательства по поставке оборудования и материалов перед клиентами в разных странах, ведущими исследования, тестирования и разработку вакцин против COVID-19. У заказчиков в России и СНГ, где направление "Лаборатория и Сервис" (ООО "Сарториус РУС») возглавил новый генеральный директор - Евгений Владимирович Шохин, такая надежность и пунктуальность вызвали благодарность и множество положительных отзывов.

О мерах, позволивших нарастить производство и соблюдать сроки поставки, и о решениях для поддержки ученых, находящихся на переднем крае борьбы с коронавирусом, мы беседуем с Ариной Алексеевной Хартуковой, специалистом ООО «Сарториус РУс» по системам водоподготовки и дозирующему оборудованию.

Пандемия коронавируса затронула всех. Как она отразилась на бизнесе компании Sartorius? Каких изменений в производственных и бизнес-процессах потребовала?

Будучи одним из мировых лидеров в производстве оборудования и расходных материалов для лабораторий и фармацевтических производств, компания Sartorius в полной мере ощутила влияние коронавируса. В новых условиях часть продукции нашей компании, например дозаторы, наконечники к ним, оборудование для исследования и разработки вакцин, одноразовые решения для производства вакцин, а также для контроля их качества во время пандемии, стали востребованы как никогда ранее.

Чтобы не останавливать производство и удовлетворить возросший спрос, руководству компании пришлось в короткие сроки принять ряд антикризисных шагов. Приоритетами были забота о здоровье сотрудников и обеспечение для них максимальных 
мер безопасности. Многим предоставлена возможность удаленной работы. Эти действия были важны еще и потому, что в условиях пандемии заболевание одного работника производства ставит под угрозу закрытия нескольких цехов. Своевременные и правильные меры, предпринятые нашим руководством, позволили компании Sartorius поддержать уже имеющиеся мощности, нарастить темпы выпуска продукции и запасы и даже перевести на трехсменную работу часть наших производств, чтобы обеспечить возросший спрос.

Решающую роль в организации и координации нашей деятельности сыграла надежная IT-инфраструктура компании. Благодаря ей, мы постоянно и активно поддерживали устойчивую связь с нашими клиентами и между отделами, в том числе и с сотрудниками, работающими удаленно. Налаженные устойчивые коммуникации позволили сохранить темпы своевременных и бесперебойных поставок.

Часть введенных руководством временных антикризисных мер оказалась настолько эффективной, что их решено превратить в постоянные рабочие процессы.

Важно отметить, что, несмотря на все события текущего года, компании Sartorius удалось успешно завершить начатые до пандемии приобретения. Она стала владельцем части бизнеса направления Life Science компании Danaher, компании Biological Industries (BI), разработчика сред для культивирования клеток, а также портфеля микроносителей компании SoloHill. Как видите, мы продолжаем расширять свои позиции на рынке и планируем сохранять этот тренд в будущем.

Какие решения компании Sartorius помогают исследователям, которые занимаются изучением COVID-19 и разработкой вакцин?

Компания Sartorius поддерживает специалистов в трех направлениях. Первое - это диагностика COVID-19. Для максимальной точности тестов и возможности их применения нужны правильные дозы реагентов и исследуемой биологической жидкости. Большинство тестов на COVID-19 выполняются методами ПЦР и ИФА, которые чувствительны к различным видам контаминаций.

В этих особых условиях пипеточные дозаторы Sartorius в комплекте с наконечниками являются практически идеальным решением, так как наряду с уникальной метрологией обеспечивают надежную защиту от всех видов загрязнения благодаря полностью автоклавируемым дозаторам и стерильным наконечникам.

В нашем арсенале есть решение для точного и быстрого определения концентрации вируса в воздухе на основе уникальных желатиновых фильтров.
Оно сейчас активно применяется в Китае и успешно используется в других странах. К сожалению, в России это решение еще не получило широкого распространения из-за длительности процессов, связанных с регистрацией, и ряда норм методической и законодательной базы. Тем не менее, мировая практика его использования дает основания для оптимизма, так что мы будем продолжать продвижение этого решения на рынок России.

Второе направление поддержки борьбы с COVID-19 это исследования и разработки. Здесь у Sartorius есть целый ряд инструментов, позволяющих биофармацевтическим R\&D-отделам сократить время разработки вакцин и лекарств с 1-1,5 лет до 1-3 месяцев. Многие из этих решений, обеспечивающих разработку и лабораторный контроль качества, а также сопутствующие процессы (точное задокументированное взвешивание, приготовление растворов с использованием ультрачистой воды, ускорение выделения и очистки целевого продукта с приспособлениями для лабораторной фильтрации) уже внедрены и применяются в нашей стране.

И, наконец, третье направление - это оборудование для производства вакцин на основе одноразовых систем. Преимущество таких решений заключается в том, что они позволяют в максимально сжатые сроки наладить производство даже в помещениях не самого высокого класса чистоты, так как вся линия полностью замкнута и защищена от контаминации. Благодаря коннекторам с асептическими сборками возможна быстрая модификация линий, а также наращивание мощностей.

Таким образом, по всем трем направлениям компания Sartorius является практически незаменимым помощником специалистов, работающих на передовой линии борьбы с распространением вируса и последствиями пандемии.

\section{Кризис для бизнеса - это одновременно} и стресс, и новые возможности для развития, новые ниши. Какие шансы дает этот коронакризис производителям лабораторного оборудования? Каким, на ваш взгляд, будет новый вектор развития этого рынка? Появления каких инновационных разработок можно ожидать в ближайшее время?

Как относиться к кризису, вызванному COVID-19, каждая компания решает в рамках своей стратегии. Мы в компании Sartorius видим в нем мощный импульс, ускоряющий наше развитие в самом широком смысле, начиная с отношений внутри команд и заканчивая совершенствованием имеющихся и выводом новых продуктов на рынок. 
На мой взгляд, вектор развития рынка лабораторного оборудования можно определить тремя словами: скорость, эффективность, ответственность. Сам факт возникновения пандемии, охватившей всю планету, показал, что в нашем мире все очень быстро и неожиданно меняется, поэтому скорость реакции на перемены, скорость вывода новых продуктов, скорость внедрения новых научных разработок будут иметь очень большое значение. Кто успеет за изменениями, тот будет в авангарде.

Эффективность - это получение максимального результата за минимальный срок. В новых реалиях невозможно получать быстрый и надежный результат на устаревшем оборудовании. Думаю, будут развиваться направления продуктов, способных быстро, качественно и с минимальным вмешательством оператора получать точные данные, таких как, например, наши приборы Incucyte и ForteBio. Также я вижу вектор развития решений для высокочувствительного экспресс-анализа, примером которых могут служить тесты на наличие микоплазмы.

Ответственность - важный параметр и очень объемный. Это ответственность за качество оборудования, за надежность и бесперебойность поставок, за послепродажное обслуживание и, наконец, за результат, который получает пользователь.

Думаю, что этот тренд отлично коррелирует с ценностями компании Sartorius. Их тоже три: постоянство, открытость, удовольствие. Мы постоянны в повышении эффективности и ответственности перед партнерами и пользователями, открыты ко всему новому и стремимся совершенствоваться. И делаем все это с большим удовольствием.

Вы считаете, что уже пришло время участвовать в крупных офлайн-мероприятиях, таких как выставка "Аналитика Экспо"?
Приборы компании Sartorius уже являются частью рабочего оборудования на многих фармацевтических предприятиях, на производстве, в R\&D-лабораториях, в отделах контроля качества. И прямое общение с заведующими и специалистами лабораторий, отделов закупок, учеными и руководителями для нас один из наиболее ценных моментов работы. Мы постоянно стремимся поддержать профессионалов в различных областях деятельности и получаем заряд энергии от того, что наши знания и опыт, которыми рады делиться, помогают совершенствовать рабочие процессы, делать их быстрее, проще, эффективнее.

В условиях, когда в мире идет нешуточная борьба с COVID-19, компании Sartorius важно показать, что она сейчас с теми, кто неустанно работает над контролем вспышки пандемии и над разработкой вакцин. Для этого как нельзя лучше подходит площадка выставки "Аналитика Экспо", в которой мы, к слову, постоянно участвуем.

В этом году мы представим продукты и решения, отвечающие всем запросам и требованиям специалистов, работающих на переднем крае борьбы с пандемией:

- лабораторные решения, помогающие в диагностике COVID-19;

- средства контроля воздуха на наличие в нем коронавируса;

- решения для разработки вирусных вакцин и векторов.

Посетители выставки смогут увидеть оборудование, оценить его возможности и познакомиться с практикой и областями применения.

\section{Спасибо за интересный рассказ.}

С А.А.ХХатуковой беседовала А.Е. Крылова
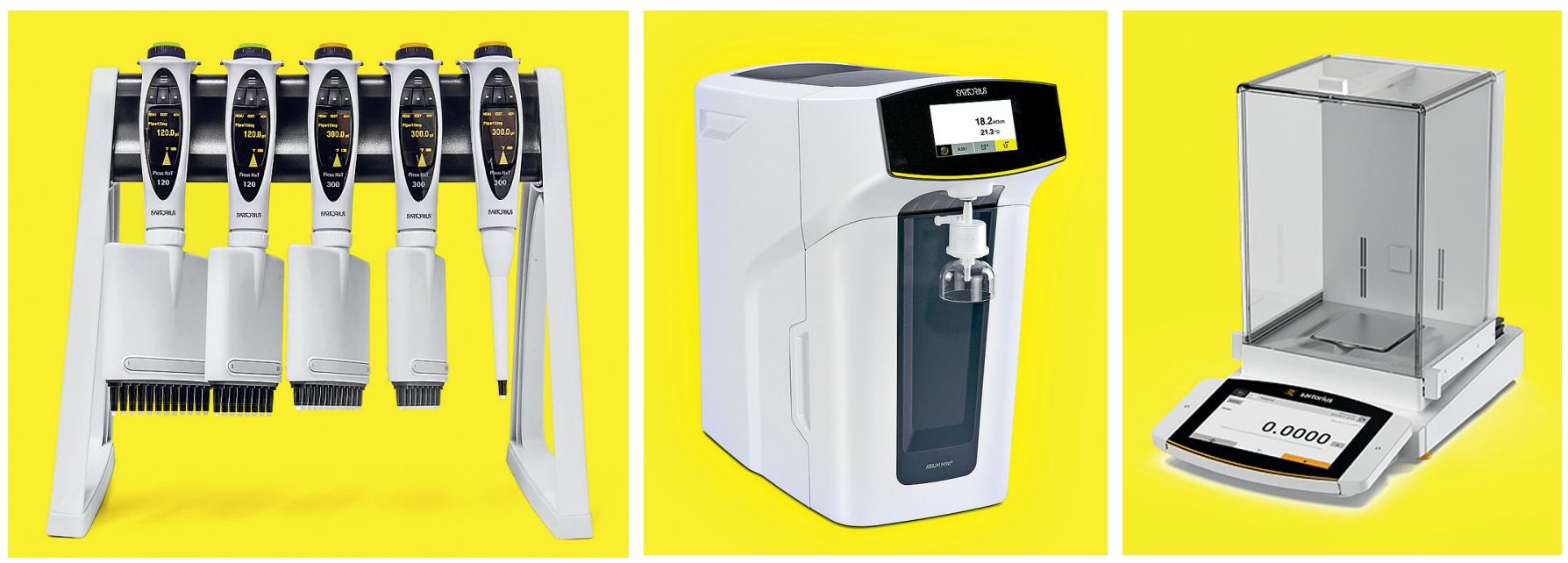


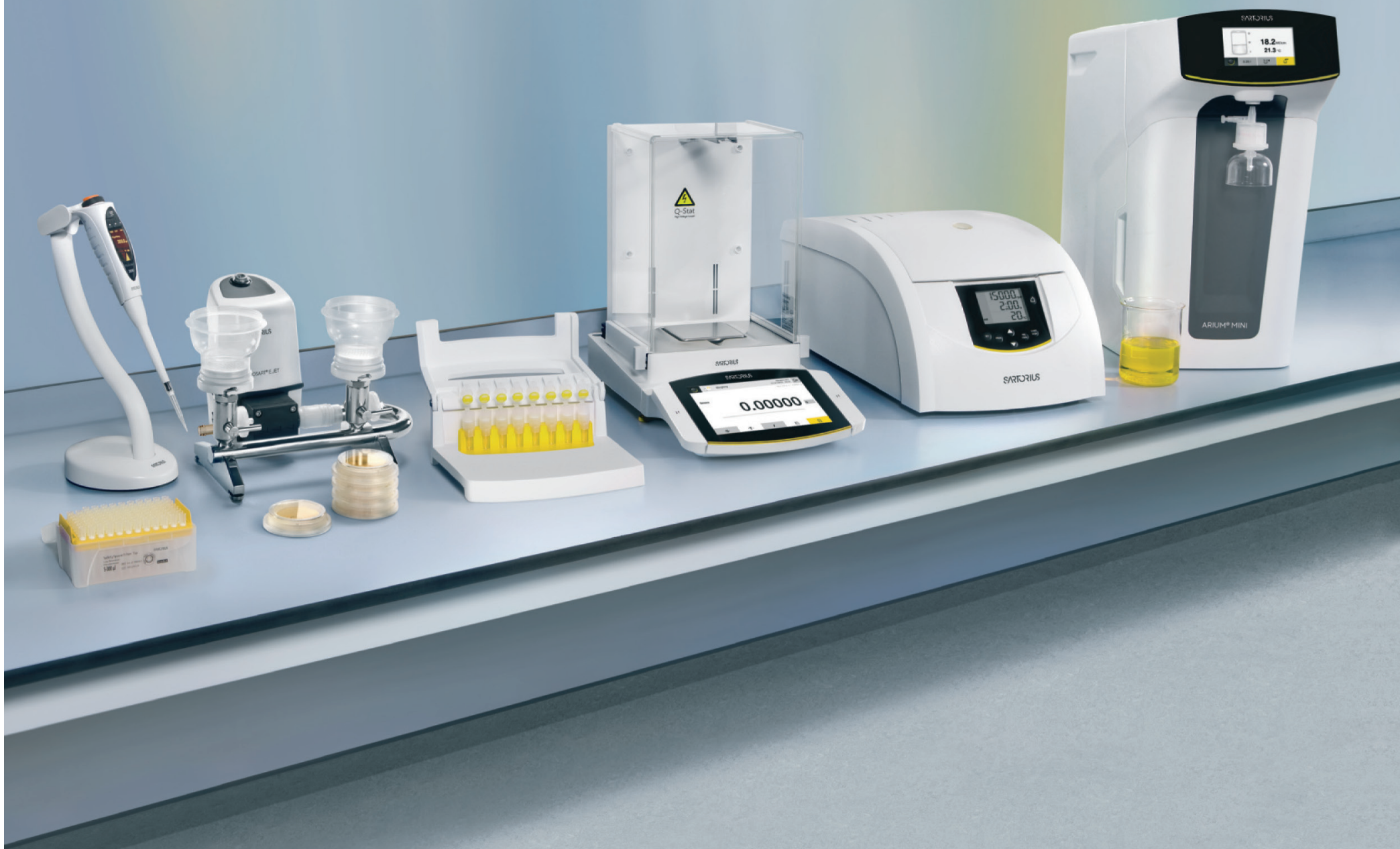

Лабораторные решения для

Simplifying Progress тестирования на COVID-19

Надёжный партнёр в области лабораторной диагностики, мониторинга воздуха и разработки вакцин

(स्रि Подробнее на: www.sartogosm.ru/covid_19_reshenia.html 